\section{Effect of Magnification during Post Space Preparation on Root Cleanness and Fiber Post Bond Strength}

Natércia Rezende da Silva ${ }^{1} \mathbb{B}$, Monise de Paula Rodrigues ${ }^{1} \mathbb{B}$, Aline Aredes Bicalho $^{2}$, Raissa Albuquerque de Deus ${ }^{1}{ }^{\circledR}$, Priscilla Barbosa Ferreira Soares $^{3}$, Carlos José Soares ${ }^{1}$ (D)
'Department of Operative Dentistry and Dental Materials, School of Dentistry, UFU- Universidade de Uberlândia, Uberlândia, MG, Brazil ${ }^{2}$ Technical Health School, UFUUniversidade de Uberlândia, Uberlândia, MG, Brazil

${ }^{3}$ Department of Periodontology and Implantology, School of Dentistry, UFU- Universidade de Uberlândia, Uberlândia, MG, Brazil

Correspondence: Prof. Dr. Carlos José Soares, Avenida Pará, 1720, Bloco 4L, Anexo A, 38400-902 Uberlândia, MG, Brasil. Tel: +55-34-3225-8106. e-mail: carlosjsoares@ufu.br

Key Words: bond strength, fiber glass post, magnification devices, surgical microscope, surgical magnifying glass.

\section{Introduction}

Post debonding has been described as the most common complications of adhesively cemented fiber pots (1). The endodontic cement used to seal the root canal, as well as the density and orientation of the root dentin tubules and deposition of cementum and secondary dentin are factors that may compromise the fiber post retention (2). The residues of endodontic sealer accidentally left on the root canal walls, might originate defects of polymerization within the cement and this could affect the bond strength of a post to root dentin (3). Moreover, the voids that may be introduced within the cement layer, as a result of luting manipulation and root insertion and inadequate cement thickness are contributing factors that can possibly affect the quality of adhesion (4-7). Histological characteristics of the root dentin following endodontic treatment and the properties of the different bonding materials make the cementation of fiber posts a challenging procedure $(8,9)$.

The self-adhesive resin cement has primary adhesion mechanism based on the micromechanical retention and chemical interaction between the monomer acidic groups and hydroxyapatite (3). The multifunctional monomers with phosphoric acid groups simultaneously demineralize and infiltrate enamel and dentin (3). Self adhesive cements have been reported as incapable of removing the smear layer (10). Consequently, they are unable to etch through the smear layer formed after the post space preparation (3). The removal of the smear layer is indicated during the biomechanical preparation of the root in order to allow better infiltrate the collagen, increasing the contact surface of the filling material with dentin and to obtain properly cleaned dentin surfaces $(11,12)$.

The use of a surgical microscope while performing mechanical cleaning during post space preparation has been reported to improve the bond strength of a fiber glass post to dentin (13). It is also important to ensure that all gutta-percha remnants are removed (13). Magnifying aids are becoming increasingly more common in dental practices and attention must be paid especially to the early onset of presbyopia around the age of 40 (14). Optical aids such as loupes or microscopes should be used early enough to compensate for individual or a generated visual deficiency (14). Professionals that use loupes and microscopes are convinced that these instruments have advantages and improve both the quality and ergonomics of their work (14). Intraradicular visual tests in a simulated clinical setting 
objectively demonstrated the significance of the operating surgical microscope for endodontic acuity and the visual acuity, with the microscope was not dependent on the location within the endodontic system or on the dentists' age (15). The microscope was the only means of achieving measurable results inside the root canal, irrespective of the age of the examiner (15).

Previous study, demonstrated that no significant improvement of clinical and radiographic outcomes was found among patients treated using magnifying loupes, surgical microscope or endoscope in endodontic procedures (6). Surprisingly, little studies about the visual acuity of dentists, the influence of the different optical devices and the relationship between visual acuity and precision in dental work has been published (16). Other study, demonstrated that scaling and root planning performed with magnification loupes before tooth extraction was more efficient than when scaling and root planning was performed without magnification loupes. The use of magnification loupes caused less damage to the tooth surface (17). The benefit of use of magnification still be inconclusive in different clinical procedures.

High-resolution micro-computed tomography (microCT) can measure the volume of three-dimensional shapes such as canals and gaps, analyzing the resin cement thickness and the voids presence around post materials (18). This methodology has been proved to be a powerful non-destructive 3D analysis, rapid, and powerful tool for visualizing the void parameters, the resin matrix, the internal structure and mechanical properties overcoming the limitations of the conventional methods $(5,6,19-23)$.

Thus, the aim of this study was to investigate the effect of visualization method for post space preparation on root cleanness and on glass fiber post bond strength. The null hypotheses tested were: 1 ) that the micro-CT analysis would not show difference on residue remnants into the root canal after post space preparation using different magnification devices microscope, loupes and naked eyes; 2) that the different levels of root canal (coronal, middle and apical thirds of post space dentin) would not influence the push-out bond strength (PBS).

\section{Material and Methods}

\section{Sample Selection and Root Canal Preparation}

This study was approved by the local Ethics Committee (Protocol 227/09). Single-rooted permanent human maxillary central incisors with similar root morphology were obtained from a pool of extracted teeth and stored in distilled water at $4^{\circ} \mathrm{C}$ until use. The specimens were decoronated by transversally sectioning the roots at 15 $\mathrm{mm}$ from the apex with a double-faced diamond disc (KG Sorensen, Barueri, SP, Brazil) at a low speed with air/water spray coolant. Roots having canals with larger diameters than $1 \mathrm{~mm}$ were discarded. All roots were measured with digital caliper (Mitutoyo, Brazil) in the mesio-distal and bucco-lingual cervical third region. By means of the mean of these measures, thirty roots whose dimensions did not have variation greater than $10 \%$ were selected. Teeth with caries, cervical erosion, previous endodontic treatment, post or crown and oval or long oval root canal were also excluded. Roots were endodontically treated and divided randomly into three groups $(n=10)$ according to the method of magnification used for post space preparation inspection: Control, using naked eye; loupe, using a dental surgical 3x magnifying glass; surgical microscope, using a $6 x$ surgical microscope.

The root canal systems were located using $10 \mathrm{~K}$-file (Dentsply Malleifer, Petrópolis, RJ, Brazil) which was introduced into the root canal until it was visible at the apical foramen. The working length was determined to be $1.0 \mathrm{~mm}$ less than this length. The root canals were shaped by rotary instruments (ProTaper system, Dentsply Malleifer, Petrópolis, RJ, Brazil) sequenced in order (SX,S1,S2,F1,F2,F3,F4) applying the crown-down technique. One rotary kit was used to prepare 5 specimens and then replaced. Throughout the preparation process, the root canals were irrigated with $2.5 \%$ sodium hypochlorite (Chlorine Rio, São José do Rio Preto, SP, Brazil) using a syringe and a 27-gauge needle throughout progression of file sizes. Final irrigation was done with 17\% ethylene diamine tetra acetic acid (EDTA; Biodynamics, Ibiporã, PR, Brazil) for three minutes followed by $2,5 \% \mathrm{NaOCl}$ solution for one minute and with $5 \mathrm{~mL}$ physiologic saline solution $(\mathrm{NaCl})$ to remove the remaining debris. The instrumented root canals were dried with sterile paper points and immediately obturated by lateral condensation, the root canal was filled with a gutta-percha master cone F4 ProTaper Universal (Dentsply), conventional gutta-percha accessory cones and calcium hydroxide cement (Sealer 26; Dentsply, Sao Paulo, SP, Brazil). Root canal opening was sealed with resin modified glass ionomer cement (Vitremer; 3M-ESPE, St Paul, MN, USA). The endodontically treated roots were stored at $37 \mathrm{C}$ and $100 \%$ relative humidity for 7 days.

\section{Micro-CT Analysis}

Each specimen was air-dried, mounted on a custom attachment and scanned using a commercially available high-resolution micro-CT system (SkyScan 1272; BrukermicroCT, Kontich, Belgium). The scanner operated at 100 $\mathrm{kV}$ and $100 \mathrm{~mA}$ (0.11-mm Cu filter). The resolution used was 1224/820 cross-sectional pixels' size and intersection distances were $20 \mu \mathrm{m}$, which resulted in 380 transverse cross sections per specimen. The scanning was performed 
at $180^{\circ}$ rotation around the vertical axis, a camera exposure time of $1000 \mathrm{~ms}$, a rotation step of $0.5^{\circ}$, frame averaging of 2 and random movement of 20. Each specimen was scanned for a total of $35 \mathrm{~min} 41 \mathrm{~s}$. Images of each specimen were reconstructed using NRecon version 1.6.10.1 (BrukermicroCT). For each tooth, evaluation was performed for the full canal length in approximately 380 slices per specimen. CTAn v.1.14.4.1 software (Bruker-microCT) was used for the 3-dimensional (3D) quantitative analysis. The volumes of interest for the endodontic sealer of the root were selected. The volumes of gutta-percha and endodontic cement inside the region of interest were analyzed. CTVol v.2.2.3.0 software (Bruker-microCT) was used for three-dimensional visualization and qualitative evaluation of the specimens.

\section{Post Space Preparation}

One trained operator prepared root canal and the post space. The root canal relief was performed to remove the gutta-percha to a depth of $10 \mathrm{~mm}$. The thirty roots selected were randomly assigned to 3 groups $(n=10)$ by using www.ramdom.com, according to the magnification device used to prepare the post space: Control, using naked eye; loupe, using a dental surgical 3 using a dental surgical $3 \times$ magnifying glass; surgical microscope, using a $6 \times$ surgical microscope.

Control Group: Naked eye, after post space preparation with a heat condenser (Paiva condenser; Golgran, São Paulo, $\mathrm{SP}$, Brazil) used at $10 \mathrm{~mm}$ using no magnification. Then, a Gates Glidden $n^{\circ} 5$ bur was used at $8 \mathrm{~mm}$, and a specific bur of the post system (White Post DC \#2; FGM, Joinville, $\mathrm{SC}$, Brazil) with dimensions similar to a glass fiber post (height $20 \mathrm{~mm}$, higher and lower diameter $1.8 \mathrm{~mm}$ and 1.1 $\mathrm{mm}$, respectively) was used at $10 \mathrm{~mm}$ (24). The post space was cleaned by copious irrigation with distillate water. The canals were dried with paper points. All procedures were performed under reflector lighting.

Loupe Magnification Group: Cleaning with a dental surgical magnifying glass $3 x$ with led light (Goldensun, Jiangsu, China -Mainland). The same post space preparation procedure described in the control group was performed by using 3.0x magnification loupes (Goldensun, Jiangsu, China -Mainland) and physically determined working distance of $420 \mathrm{~mm}$.

Microscope Magnification Group: The same post space preparation procedure described in the control group was performed by using a microscope (Alliance Comercial, São Carlos, SP, Brazil) which presented magnification factor of $6.0 x, 10 x, 16 x, 25 x$ and $40 x$. However, the magnification factor used in this study was $6.0 \times$ and physically determined working distance of 200-250 mm.

After the post space preparation, the roots were submitted to a new micro-CT scanned reconstruction, applying the initial parameter settings as described previously.

\section{Glass Fiber Post Cementation}

The glass fiber post was etched with 24\% hydrogen peroxide for $1 \mathrm{~min}$, was rinsed with distilled water and air dried. After that a silane agent was applied for $1 \mathrm{~min}$ (Silano; Angelus, Londrina, PR, Brazil). All roots were dried with paper points and the fiber posts were cemented using handled mix self-adhesive resin cement (RelyX U200, 3M-ESPE) that was prepared according to the manufacturer's instructions, introduced into the canal with a K-file and the posts were covered with cement and slowly seated under digital pressure for $5 \mathrm{~min}$. After $5 \mathrm{~min}$ (22), the resin cement was light-cured at each coronal root surface (buccal, lingual and occlusal) for 40 s using a halogen curing lamp (Optilux 501; Kerr Corporation, Orange, CA, USA) with $1000 \mathrm{~mW} / \mathrm{cm}^{2}$ light intensity. The specimens were stored in humidity $100 \%$ at $37{ }^{\circ} \mathrm{C}$ for 7 days.

\section{Push-out Bond Strength Test}

The samples were fixed in acrylic plate of $20 \mathrm{~mm} \times 20$ $\mathrm{mm}$ with adhesive cyanoacrylate (Super Bonder, Loctite, $\mathrm{SP}$, Brazil) and were transversely sectioned by using the water-cooled low-speed diamond saw (Isomet1000; Buehler Ltd, Lake Bluff, IL). Two 1.0-mm thick slices from the apical, middle and coronal root regions were obtained. Load indenter tips of $1.5 \mathrm{~mm}$ and $2.5 \mathrm{~mm}$ base were used for the cervical and middle thirds, and $1.0 \mathrm{~mm}$ tip and $2.0 \mathrm{~mm}$ base were used for the apical third (24). Diameter and thickness of the specimens were obtained by using a stereomicroscope and digital micrometer (Mitutoyo, Santo Amaro, SP, Brazil) with 0.01-mm accuracy digital camera. Each slice was submitted to the push-out bond strength test (DL500; EMIC, São José dos Pinhais, PR, Brazil), with the load applied in the apical-coronal direction at a crosshead speed of $0.5 \mathrm{~mm} / \mathrm{min}$. The maximum load at failure was recorded in Newton ( $\mathrm{N}$ ) and converted into Mega Pascal (MPa) by dividing the load applied by the bonded area (A), calculated by using the following formula: $A=\pi(R 1+R 2) \sqrt{ } R 1-R 2) 2+h 2$; where $\pi$ is a constant value of $3.14, r$ and $R$ are the smallest and the largest radius, respectively, of the cross-sectioned tapered post, and $\mathrm{h}$ is the thickness of the section.

\section{Failure Mode Analysis}

To determine failure mode the calibrated operator used a stereomicroscope at 40x magnification, (Mitutoyo, Tokyo, Japan). Failures were classified into 1 of 5 categories: 1) adhesive between post and resin cement; 2) between resin cement and root dentin; 3) mixed, with resin cement covering partially of the post surface; 4) cohesive within 
the fiber post and 5) cohesive within the dentin.

\section{Statistical Analysis}

PBS data were statistically analyzed using a one-way analysis of variance with repeated measurement test and the Tukey post hoc test to evaluate differences in visualization methods study factor and the repeated measurement being root regions. The volume of endodontic filling material was analyzed using 1-way analysis of variance test and the Tukey post hoc test to evaluate differences in visualization methods. The significance level was set at 5\%. All statistical analyses were performed using Sigma Plot 12.1 (Stata Corp, College Station, TX).

\section{Results}

\section{Push-out Bond Strength Test}

PBS means and standard deviations are shown in Figure 1A. One-way ANOVA showed significant differences only for the factor "root region" ( $p=0.012)$. No difference was found for "method of visualization" ( $p=0.556)$ and neither for the interaction between the factors $(p=0.324)$. The Tukey test showed that the cervical region had higher values than apical region irrespective of the visualization method used. adhesive between the fiber post and resin cement.

\section{Micro-CT Analysis}

The micro-CT analysis showed no difference on residue remnants into the root canal after post space preparation (Fig. 2). The residue remnants were located only close to the end of the post space preparation resulted by shape of the drill used for post preparation.

\section{Discussion}

Previous researches demonstrated that only microscope allowed the observation of structures much smaller than $0.06 \mathrm{~mm}$ inside the root canal, in all locations, independent of age (15). The unaided vision and loupes with an integrated light source could not provide any measurable vision inside the root canal (15). Dentists over 40 years of age were dependent on the microscope to inspect the root canal system (15).

The vision of dentists using a surgical microscope by the miniaturized eye charts in tooth cavities is considered adequate for magnifications of $4 \times$ and $6.4 \times(26)$. Higher magnifications, common in fact, when working clinically with the surgical microscope, could not be evaluated. Also, the comparably low microscopic magnification of $6 x$, similar in this study, is a compromise between ergonomics and vision, but allowed the dentists to see structures much

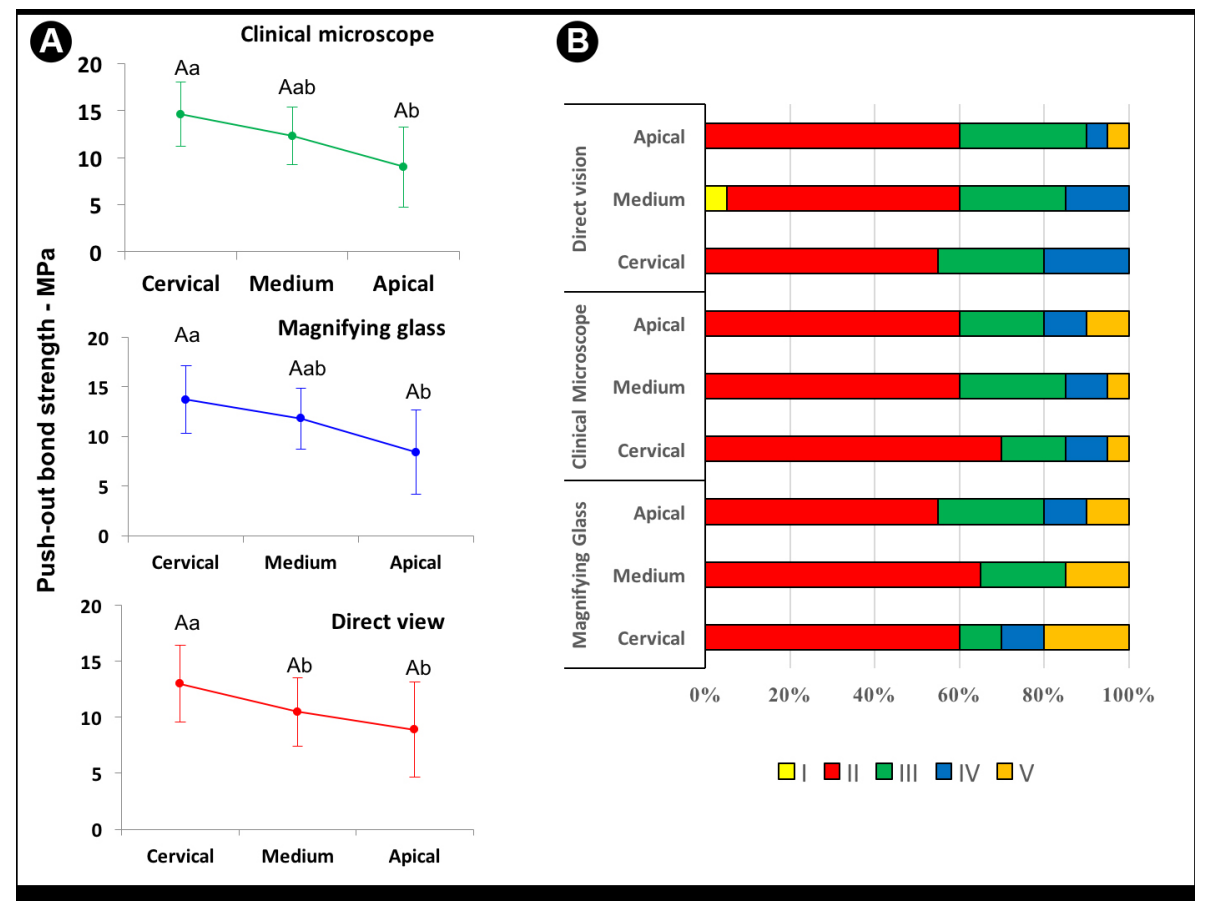

Figure 1. A: Mean and Standard Deviations of PBS (MPa) for the visualization methods and root regions. Different letter means significant difference, upper caser letter used to compare visualization methods and lower caser letter for root regions; B: failure mode distribution expressed as percentage: I, adhesive between post and resin cement; II, between resin cement and root dentin; III, mixed, with resin cement covering partially of the post surface; IV, cohesive within the fiber post; $V$, cohesive within the dentin. 
smaller than $0.06 \mathrm{~mm}$ in all locations (15). The results of the impact of loupes and microscope on vision in endodontic were similar in a root canal at the medium third that represents the depth of $5 \mathrm{~mm}$ and at the apex (15).

In the present study, magnification device as microscope and loupe did not influence the retention of fiber posts. The absence of the crown and the realization of the experimental procedures in a laboratorial situation can facilitate the root canal cleanness, explaining the obtained results. Anterior teeth were used in this study. They have straight roots with similar length, round internal anatomy and diameter equivalent and hence this samples prepare was not conducted intraorally at the actual clinically relevant location of interest. Therefore, all the work was done at direct view.

Other reported study, found no statistical difference in free flap outcomes and safety under loupe magnification compared with the operating microscope. It was the first study to demonstrate these findings with 2 microsurgeons both in their first 3 years in practice, with similar training and experience, operating at the same institution and given the same resources, each using either microscopes or loupes for microsurgery (27). Although, has been described that the molars treatment has a statistically significant greater probability of success providing best available evidence on the influence of high-power magnification rendered by the surgical microscope and premolars and anterior teeth was slightly greater but was not statistically significant (28). It was considered the difficult by anatomical location molar teeth that complicating the access for instruments and the proper positioning of the magnifier, and, consequently, a correct view angle (28). In another situation, the surgical microscope improved the bonded strength of fiber glass posts to bovine dentin of anterior teeth (13).

Additionally, PBS values higher in the cervical region and middle thirds than the apical third could be attributed to the higher stress concentration of the apical slice due the higher porosity on apical region because the difficulty of the resin cement insertion and the possibility of the air confined during post insertion (4). High polymerization shrinkage stresses have been reported in resin cements because of the high $\mathrm{C}$-factor in the root canal (25). Under shrinkage effect, gaps occur when those stresses are higher than bond on adhesive interface. Also, light intensity that reaches the cervical and middle thirds provided higher bond strengths to dentin (10). Limited light-transmitting ability of fiber posts can reflect in a reduction of the resin cement conversion degree with increased length of simulated root canals (3). Hence, the most prevalent failure mode observed in this study reinforce the statement that the most sensible interface is between dentin and resin cement. It is the interface where the higher stress concentration is located.

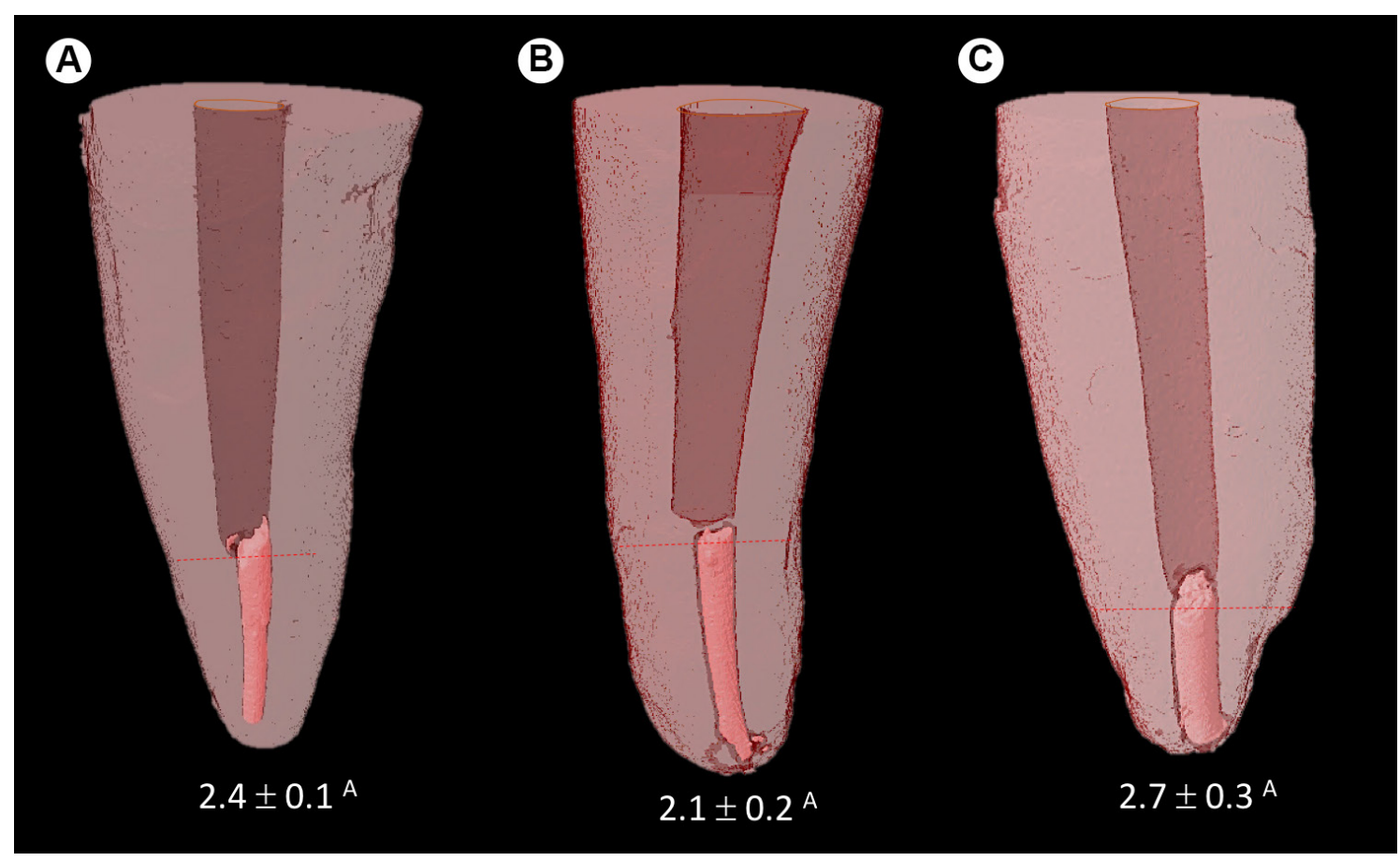

Figure 2. Lateral vision of 3D reconstruction qualitative analysis teeth after post space preparation using different visualization methods: A: surgical microscope; B: magnification glass; C: Direct view. Mean and standard deviations of volume of endodontic filling material of post space preparation (\%) quantitative analysis for all visualization methods. 
In conclusion, the micro-CT analysis showed no difference on endodontic filling material into the root canal after post space preparation using surgical microscope, loupes and naked eye as visualization methods, and the use of a microscope during post space and or loupes had no effect on push-out bond strength. However, the cervical region had higher values than apical region irrespective of the visualization method used.

More studies to evaluate the effect of the higher magnification device in molars teeth, with simulated clinical setting using a phantom head on the patient's dental chair, during the post space preparation, on fiberglass post bond strength to root dentin are recommended. Also, there is the necessity for randomized clinical trials for confirming the real effectiveness of the magnification to make an informed decision for clinical practice.

\section{Resumo}

Avaliar o efeito do método de visualização durante o preparo do espaço do pino sobre o remanescente de material obturador endodôntico e sobre a resistência adesiva do pino de fibra de vidro. Trinta incisivos centrais superiores humanos com canal radicular circular foram selecionados, foram desobstruidos a $15 \mathrm{~mm}$ e obturados. Os dentes foram divididos em 3 grupos $(n=10)$, de acordo com o método de ampliação utilizado para $\vec{z}$ inspeção do preparo: Controle, usando olho nu; lupa, usando uma lupa ¿ cirúrgica 3x cirúrgica; microscópio cirúrgico, usando um microscópio cirúrgico $6 x$. As raizes foram digitalizadas usando micro-CT antes e após a preparação do espaço para avaliação de resíduos remanescentes. Os pinos de fibra foram cimentados com cimento resinoso autoadesivo (RelyX $\therefore$ U200, 3M-ESPE). Duas fatias de $1 \mathrm{~mm}$ de espessura dos terços cervical, médio e apical foram submetidas ao teste push-out (PBS). Os padrões de falhas foram classificados. Os dados de PBS foram analisados usando análise de variância em dois fatores com medição repetida e o teste de Tukey. 0 nivel de significância foi estabelecido em 5\%. Resultados: 0 método de visualização não teve efeito no $\mathrm{PBS}(\mathrm{p}=0,556)$. A região cervical apresentou valores maiores que a região apical, independentemente do método de inspeção $(p=0,012)$. A falha adesiva entre o cimento resinoso e a dentina foi o modo de falha prevalente para todos os grupos. A análise de micro-CT não mostrou diferença na limpeza da raiz no canal radicular após a preparação do espaço do pino. Conclusão: 0 uso de dispositivos de ampliação como lupas e microscópios durante a realização de preparo não melhora o PBS e não afetou a permanência do material obturador remanescente de dentes anteriores.

\section{Acknowledgements}

The authors thank Supported by the National Counsel of Technological and Scientific Development (CNPq), Coordination for the Improvement of Higher Education Personnel (CAPES) and Foundation of the State of Minas Gerais (FAPEMIG). The authors deny any conflicts of interest related to this study.

\section{References}

1. Bitter K, Perdigão J, Exner M, Neumann K, Kielbassa A, Sterzenbach G. Reliability of fiber post bonding to root canal dentin after simulated clinical function in vitro. Oper Dent 2012;37:397-405.

2. Ferrari $M$, Mannocci $F$, Vichi $A$, Cagidiaco $M C$, Mjör IA. Bonding to root canal: structural characteristics of the substrate. Am J Dent 2000;13:255-260.

3. Goracci C, Sadek FT, Fabianelli A, Tay FR, Ferrari M. Evaluation of the adhesion of fiber posts to intraradicular dentin. Oper Dent 2005;30:627-635.
4. Da Silva NR, Aguiar GC, Rodrigues Mde P, Bicalho AA, Soares PB,

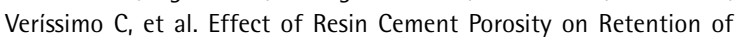
Glass-Fiber Posts to Root Dentin: An Experimental and Finite Element Analysis. Braz Dent J 2015;26:630-636.

5. Lorenzoni FC, Bonfante EA, Bonfante G, Martins LM, Witek L, Silva NR. MicroCT analysis of a retrieved root restored with a bonded fiberreinforced composite dowel: a pilot study. J Prosthodont 2013;22:478483.

6. Rengo C, Spagnuolo G, Ametrano G, Juloski J, Rengo S, Ferrari M. Micro-computerized tomographic analysis of premolars restored with oval and circular posts. Clin Oral Investig 2014;18:571-578.

7. Rodrigues RV, Sampaio CS, Pacheco RR, Pascon FM, Puppin-Rontani RM, Giannini M. Influence of adhesive cementation systems on the bond strength of relined fiber posts to root dentin. J Prosthet Dent 2017;118:493-499.

8. Goracci C, Tavares AU, Fabianelli A, Monticelli F, Raffaelli O, Cardoso $\mathrm{PC}$, et al. The adhesion between fiber posts and root canal walls: comparison between microtensile and push-out bond strength measurements. Eur J Oral Sci 2004;112:353-361

9. Suzuki TY, Gomes-Filho JE, Gallego J, Pavan S, Dos Santos PH, Fraga Briso AL. Mechanical properties of components of the bonding interface in different regions of radicular dentin surfaces. J Prosthet Dent 2015;113:54-61.

10. Radovic I, Monticelli F, Goracci C, Vulicevic ZR, Ferrari M. Self-adhesive resin cements: a literature review. J Adhes Dent 2008;10:251-258.

11. Alkhudhairy FI, Bin-Shuwaish MS. The effect of sodium hypochlorite and resin cement systems on push-out bond strength of cemented fiber posts. Pak J Med 2016;32:905-910.

12. Scotti $N$, CoeroBorga $F A$, Alovisi $M$, Bergantin $E$, Marchionni $S$, Pasqualini $D$, et al. Fiber-post bond strength in canals obturated with a cross-linked gutta-percha core obturator. Eur J Oral 2014;122:168-173

13. Ferreira $R$, Prado $M$, de Jesus Soares $A$, Zaia AA, de Souza-Filho FJ. Influence of Using Clinical Microscope as Auxiliary to Perform Mechanical Cleaning of Post Space: A Bond Strength Analysis. J Endod 2015;41:1311-1316.

14. Eichenberger M, Perrin P, Ramseyer ST, Lussi A. Visual Acuity and Experience with Magnification Devices in Swiss Dental Practices. Oper Dent 2015;40:e142-149.

15. Perrin $P$, Neuhaus KW, Lussi A. The impact of loupes and microscopes on vision in endodontics. Int Endod J 2014;47:425-429.

16. Eichenberger $M$, Perrin $P$, Neuhaus KW, Bringolf $U$, Lussi A. Visual acuity of dentists under simulated clinical conditions. Clin Oral Investig 2013;17:725-729.

17. Dadwal A, Kaur R, Jindal V, Jain A, Mahajan A, Goel A. Comparative evaluation of manual scaling and root planing with or without magnification loupes using scanning electron microscope: A pilot study. J Indian Soc Periodontol 2018;22:317-321.

18. Uzun IH, Malkoç MA, Keles A, Ögreten AT3. 3D micro-CT analysis of void formations and push-out bonding strength of resin cements used for fiber post cementation. J Adv Prosthodont 2016;8:101-109.

19. Caceres EA, Sampaio CS, Atria PJ, Moura H, Giannini M, Coelho PG, Hirata R. Void and gap evaluation using microcomputed tomography of different fiber post cementation techniques. J Prosthet Dent 2018;119:103-107.

20. Gandolfi MG, Parrilli AP, Fini M, Prati C, Dummer PM. 3D micro-CT analysis of the interface voids associated with Thermafil root fillings used with AH Plus or a flowable MTA sealer. Int Endod J 2013;46:253263.

21. Keles A, Alcin H, Kamalak A, Versiani MA. Oval-shaped canal retreatment with self-adjusting file: a micro-computed tomography study. Clin Oral Investig 2014;18:1147-1153.

22. Moeller L, Wenzel A, Wegge-Larsen AM, Ding M, Kirkevang LL. Quality of root fillings performed with two root filling techniques. An in vitro study using micro-CT. Acta Odontol Scand 2013;71:689-696.

23. Robinson JP, Lumley PJ, Claridge $E$, Cooper PR, Grover LM, Williams $R L$, et al. An analytical Micro CT methodology for quantifying inorganic dentine debris following internal tooth preparation. J Dent 2012;40:999-1005.

24. Novais VR, Rodrigues RB, Simamoto Júnior PC, Lourenço CS, Soares 
CJ. Correlation between the Mechanical Properties and Structural Characteristics of Different Fiber Posts Systems. Braz Dent J 2016;27:46-51.

25. Zanatta RF, Barreto Bde C, Xavier TA, Versluis A, Soares CJ. Effect of punch and orifice base sizes in different push-out test setups: stress distribution analysis. J Adhes Dent 2015;17:45-50.

26. Eichenberger M, Perrin P, Neuhaus KW, Bringolf U, Lussi A. Influence of loupes and age on the near visual acuity of practicing dentists. J Biomed Opt 2011;16:035003.

27. Ehanire T, Singhal D, Mast B, Leyngold M. Safety of Microsurgery Under Loupes Versus Microscope: A Head-to-Head Comparison of 2 Surgeons
With Similar Experiences. Ann Plast Surg 2018 Jun;80:S340-S342.

28. Setzer FC, Kohli MR, Shah SB, Karabucak B, Kim S. Outcome of endodontic surgery: a meta-analysis of the literature--Part 2: Comparison of endodontic microsurgical techniques with and without the use of higher magnification. J Endod 2012;38:1-10.

Received February 14, 2019 Accepted May 17, 2019 